\title{
Uptake of Transition Metal Ions Using Liposomes Containing Dicetylphosphate as a Ligand
}

\author{
Tamio Kamidate, ${ }^{\dagger}$ Yasunori HaShimoto, Hirofumi TANI, and Akihiko IsHIDA \\ Graduate School of Engineering, Hokkaido University, Kita-13, Nishi-8, Kita-ku, Sapporo 060-8628, Japan
}

\begin{abstract}
The uptake of $\mathrm{Cu}^{2+}$ was investigated using various types of liposomes composed of phosphatidylcholine (PC), cholesterol (Chol) and dicethylphosphate (DCP). DCP played a role as a ligand for $\mathrm{Cu}^{2+}$. Multilamellar vesicles (MLVs) were more effective for the uptake of $\mathrm{Cu}^{2+}$ compared to unilamellar vesicles prepared by the extrusion technique. The uptake efficiency of MLVs for $\mathrm{Cu}^{2+}$ was dependent on the molar ratio of DCP in MLVs. The uptake percent of $\mathrm{Cu}^{2+}$ was $92 \%$ using MLVs having a PC:DCP:Chol molar ratio of 4:3:3; $95 \%$ of the total vesicle $\mathrm{Cu}^{2+}$ was bound to DCP of the outer membrane surface of the MLVs, and the remaining 5\% of the total $\mathrm{Cu}^{2+}$ was distributed into the interior side of the MLVs. MLVs having a PC:DCP:Chol molar ratio of 4:3:3 were also effective as separation media for $\mathrm{Mn}^{2+}, \mathrm{Co}^{2+}, \mathrm{Ni}^{2+}$ and $\mathrm{Zn}^{2+}$. The uptake efficiency of the MLVs for the transition-metal ions increased in the order $\mathrm{Co}^{2+}<\mathrm{Zn}^{2+}<\mathrm{Ni}^{2+}<$ $\mathrm{Mn}^{2+}<\mathrm{Cu}^{2+}$
\end{abstract}

(Received November 9, 2001; Accepted January 15, 2002)

Microorganisms are capable of adsorbing or accumulating heavy metal ions due to metal-attracting compositions on their cell walls or via metabolism-dependent intracellular metal uptake mechanisms. Therefore, the application of microbial biomass to the recovery of toxic heavy metals from an aqueous solution has been noted in recent decades. Various kinds of microorganisms were used to remove heavy metals from the environment and industrial waste water. ${ }^{1,2}$ On the other hand, liposomes composed of natural phospholipids surfactants were used as a model of a cell, since liposomes consist of vesicular lipid bilayers that enclose a volume of aqueous solution. However, phospholipids which have markedly hydrophobic chains prevent the passage of water-soluble materials through membranes. Therefore, the transport of metal ions across the membrane of liposomes is mediated by ionophores, such as calcimycin. ${ }^{3,4}$ On the other hand, no reports have been found on the application of liposomes to biomimetic metal-sorbing media, since liposomes are hardly permeable to metal ions.

We previously applied multilamellar vesicles (MLVs) composed of phophatidylcholine (PC), cholesterol (Chol) and dicetylphosphate (DCP) to the uptake of transition-metal ions. ${ }^{5}$ MLVs composed of a PC:DCP:Chol molar ratio of 10:1:10 were effective for the uptake of $\mathrm{Cu}^{2+}$ and $\mathrm{Zn}^{2+}$ without ionophores. The uptake of $\mathrm{Cu}^{2+}$ and $\mathrm{Zn}^{2+}$ was probably due to complex formation between the metal ions and the phosphate of DCP. However, the MLVs were unable to adsorb $\mathrm{Mn}^{2+}, \mathrm{Fe}^{2+}$, $\mathrm{Co}^{2+}$ and $\mathrm{Ni}^{2+}$. Therefore, the increase in the uptake efficiency of liposomes for those metal ions could be important in order to apply liposomes to metal-sorbing media for transition-metal ions.

In this study, the factors which affect the uptake efficiency of $\mathrm{Cu}^{2+}$ were investigated in terms of the $\mathrm{pH}$, DCP concentration and liposome size. In addition, the $\mathrm{Cu}^{2+}$ content of the outer membrane surface and the interior side of the MLVs were determined. Under the optimum conditions established, MLVs

$\doteqdot$ To whom correspondence should be addressed. were applied to the separation media of $\mathrm{Mn}^{2+}, \mathrm{Fe}^{2+}, \mathrm{Co}^{2+}, \mathrm{Ni}^{2+}$ and $\mathrm{Zn}^{2+}$.

\section{Experimental}

\section{Materials}

Egg-yolk phosphatidylcholine (PC) and cholesterol (Chol) were obtained from Wako Pure Chemicals. Dicetylphosphate (DCP) was purchased from Sigma Chemical Co. Calcein $\left\{3,3^{\prime}-\right.$ bis $[N, N$-bis(carboxymethyl)amminomethyl]fluorescein $\}$ was bought from Dojindo Laboratories. The concentration of PC was calculated by using a molecular weight of 765.3. ${ }^{6}$ A $1.0 \times$ $10^{-2} \mathrm{M}$ solution of metal ions was prepared by dissolving metal salts: $\mathrm{MnCl}_{2}, \mathrm{Fe}\left(\mathrm{NH}_{4}\right)_{2}\left(\mathrm{SO}_{4}\right)_{2}, \mathrm{CoCl}_{2}, \mathrm{NiCl}_{2}, \mathrm{CuCl}_{2}$ and $\mathrm{ZnCl}_{2}$.

\section{Preparation of liposomes}

Multilamellar vesicles (MLVs) were prepared using standard methods. $^{7}$ A mixture $(16.8 \mu \mathrm{mol} \mathrm{PC}, 12.6 \mu \mathrm{mol} \mathrm{Chol,} 12.6$ $\mu \mathrm{mol}$ DCP) in chloroform was added to a $100-\mathrm{ml}$ round-bottom flask. Chloroform was removed by rotary evaporation at $25^{\circ} \mathrm{C}$ under reduced pressure and a stream of nitrogen gas forming a lipid film on the wall of the flask. After at least $1 \mathrm{~h}$ in vacuo, a $0.9-\mathrm{ml}$ portion of a $1.0 \times 10^{-2} \mathrm{M} \quad 3-(\mathrm{N}-$ morpholino)propanesulfonic acid (Mops) buffer solution $(\mathrm{pH}$ 7.5) was added into the flask and whole contents were extensively mixed on a Vortex stirrer for $15 \mathrm{~min}$ at $25^{\circ} \mathrm{C}$ to prepare MLVs.

Thus-prepared MLVs suspensions were extruded through a polycarbonate filter to prepare unilamellar vesicles. Polycarbonate filters with pore sizes of 100, 400 and $1000 \mathrm{~nm}$ were obtained from Avestin Inc. The filters were mounted in a LiposoFast ${ }^{\mathrm{TM}}$-Basic (Avestin Inc.) fitted with two $0.5 \mathrm{ml}$ Hamilton syringes. We subjected samples to 20 passes through a single filter. A numerical subscript indicated the pore size of the polycarbonate filter employed. Thus, a VET 1000 indicated that liposomes were extruded through a polycarbonate filter 
with a pore size of $1000 \mathrm{~nm}$. The size distributions of the MLVs and VETs were estimated by a laser scattering particle size distribution analyzer (LA-910, Horiba, Japan).

\section{Uptake of metal ions using liposomes}

The uptake procedure of metal ions with liposomes consisted of pipetting $0.9 \mathrm{ml}$ of liposome suspensions and a $0.1 \mathrm{ml}$ of a $1.0 \times 10^{-2} \mathrm{M}$ metal ion solution into a glass cuvette. The mixture was shaken for $30 \mathrm{~min}$ by a water bath-incubator at $25^{\circ} \mathrm{C}$. Next, the separation of free metal ions and liposomes containing metal ions was performed on a Sephadex G-50 column (column size, $10 \times 300 \mathrm{~mm}$ ). The column was equilibrated with $10 \mathrm{mM}$ Mops buffer ( $\mathrm{pH} 7.5$ ); the flow rate was $18 \mathrm{ml} / \mathrm{h}$. A $275-\mu \mathrm{l}$ portion of the mixture was applied to the column. The amounts of liposomes and metal ions eluted from the column were determined by measuring the phosphorus and metal ion in each fraction tube by an inductively coupled plasma atomic emission spectrometer (ICP-AES) with an ultrasonic neblizer (ICPS-1000IV, Shimadzu, Japan). ${ }^{8}$ The uptake percent is referred to as the mole ratio of the metal ions detected in the fraction of liposomes to the total moles of the metal ions in a liposome suspensions applied to the column.

\section{Measurement of the trapping efficiency of calcein in MLVs}

Calcein-trapped MLVs were prepared according to the procedure, except that a $1.0-\mathrm{ml}$ portion of a $5.0 \times 10^{-8} \mathrm{M}$ calcein solution was added into the flask in place of the buffer solution in the swelling of the lipid film. ${ }^{7}$ A $50-\mu$ l portion of MLVs suspensions was diluted with a $2.0-\mathrm{ml}$ portion of the buffer solution in a $1-\mathrm{cm}$ quartz cell. The fluorescence intensity $\left(F_{1}\right)$ was measured at exitation and emission wavelengths of 490 and $513 \mathrm{~nm}$, respectively. Subsequently, a $5-\mu 1$ portion of a $1.0 \times$ $10^{-2} \mathrm{M}$ of $\mathrm{Co}^{2+}$ solution was injected into the cell. Vigorous agitation by a magnetic stirrer was continued during the fluoresence measurement. The fluorescence intensity after the addition of a $\mathrm{Co}^{2+}$ solution was defined as $F_{2}$. Next, a 20- $\mu$ l portion of $10 \%$ Triton X-100 was added into the cell, thus destroying those MLVs containing calcein. The thus-obtained fluorescence intensity $\left(F_{3}\right)$ represents the equilibrium concentration of free calcein. The trapping efficiency of calceine in MLVs was calculated from:

$$
\text { trapping efficiency } \%=\left[F_{2}-\left(F_{3} \cdot r\right)\right] /\left[F_{1}-\left(F_{3} \cdot r\right)\right] \times 100
$$

where $r$ is the dilution factor due to the Triton $\mathrm{X}-100$ solution, 1.01 in the present case.

\section{Results and Discussion} Uptake of $\mathrm{Cu}^{2+}$ using $\mathrm{MLVs}$ and the recovery of $\mathrm{MLVs}$
containing $\mathrm{Cu}^{2+}$

We carried out the uptake of $\mathrm{Cu}^{2+}$ with MLVs composed of a PC:DCP:Chol molar ratio of 4:3:3. The mixture of free $\mathrm{Cu}^{2+}$ and MLVs containing $\mathrm{Cu}^{2+}$ was applied to a Sephadex G-50 column. Typical elution profiles of phosphorus and $\mathrm{Cu}^{2+}$ are shown in Fig.1. One peak was observed in the elution profiles of phosphorus and $\mathrm{Cu}^{2+}$. When MLVs containing $\mathrm{Cu}^{2+}$ were eluted from the column, the elution volume of $\mathrm{Cu}^{2+}$ coincided with that of phosphorus. Therefore, the peak observed in the elution profile is ascribed to the elution of MLVs containing $\mathrm{Cu}^{2+}$. Free $\mathrm{Cu}^{2+}$ could be eluted from the column in the range from $20 \mathrm{ml}$ to $30 \mathrm{ml} .^{5}$ However, no peak based on the elution of free $\mathrm{Cu}^{2+}$ was observed in the elution profile. This is because free $\mathrm{Cu}^{2+}$ could be adsorbed on the column.

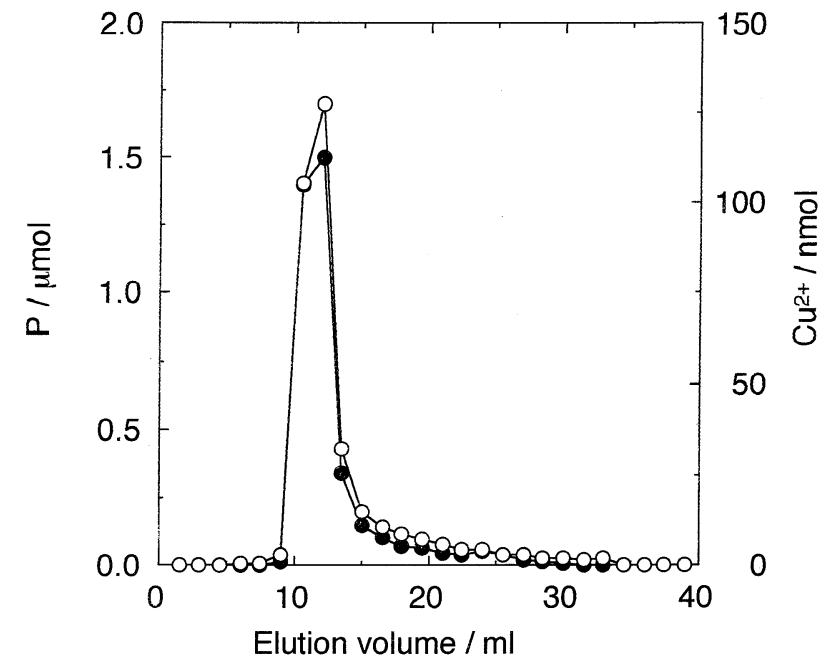

Fig. 1 Elution profiles of MLVs containing $\mathrm{Cu}^{2+}$ obtained by gelfiltration. Conditions: column, Sephadex G-50 $(10 \times 300 \mathrm{~mm})$; mobile phase, $10 \mathrm{mM}$ Mops buffer ( $\mathrm{pH} 7.5$ ); MLVs suspensions, 275 $\mu \mathrm{l}$; flow rate, $0.3 \mathrm{ml} / \mathrm{min}$; fractionation, $5 \mathrm{~min} /$ tube. ( $\mathrm{O}$ ), phosphorus; $(\bullet)$, copper.

Next, MLVs containing $\mathrm{Cu}^{2+}$ were mixed after collecting the fraction eluted from 10.5 to $15 \mathrm{ml}$. We then determined the amount of $\mathrm{Cu}^{2+}$ incorporated into the MLVs. The uptake percent of $\mathrm{Cu}^{2+}$ was $92 \%$ when MLVs composed of a PC:DCP:Chol molar ratio of 4:4:3 were used. The amount of phosphorus was also determined by ICP-AES. The amount of phosphorus in MLVs containing $\mathrm{Cu}^{2+}$ was almost equal to that in MLVs suspensions applied to the column. Therefore, MLVs containing $\mathrm{Cu}^{2+}$ were essentially excluded from the column.

\section{Optimum conditions for the uptake of $\mathrm{Cu}^{2+}$}

The effects of the mixing time, $\mathrm{pH}$ and liposome size on the uptake percent of $\mathrm{Cu}^{2+}$ were investigated using MLVs composed of a PC:DCP:Chol molar ratio of 4:4:3. The effect of the mixing time on the uptake percent was examined over the range of 5-60 min. The uptake percent was almost constant after $10 \mathrm{~min}$. Thus, the optimum mixing time was chosen to be $30 \mathrm{~min}$. We then examined the dependence of the $\mathrm{pH}$ on the uptake percent of $\mathrm{Cu}^{2+}$ in the $\mathrm{pH}$ range from 7.0 to 8.0. The uptake percent of $\mathrm{Cu}^{2+}$ was constant in the $\mathrm{pH}$ range examined. The optimum $\mathrm{pH}$ was thus chosen to be 7.5. Next, the effect of the liposome size on the uptake percent of $\mathrm{Cu}^{2+}$ was investigated using $\mathrm{VET}_{100}, \mathrm{VET}_{400}, \mathrm{VET}_{1000}$ and MLVs. As shown in Fig. 2, the MLVs were more effective for the uptake of $\mathrm{Cu}^{2+}$ compared to various sizes of the VETs. The mean diameters of $\mathrm{VET}_{100}$, $\mathrm{VET}_{400}, \mathrm{VET}_{1000}$ and the MLVs were 155, 272, 440 and 12000 $\mathrm{nm}$, respectively. This result indicates that the surface area of MLVs was remarkably greater than those of the VETs. Therefore, the increase in the surface area of the liposomes could accelerate the interaction between DCP and $\mathrm{Cu}^{2+}$, thus resulting in an increase in the uptake percent of $\mathrm{Cu}^{2+}$. However, the reason for the differences in the uptake percent between VETs is still not clear. Thus, MLVs were chosen to be used as a separation media.

The uptake percent of $\mathrm{Cu}^{2+}$ was $18 \%$ using MLVs composed of a PC:DCP:Chol molar ratio of 10:1:10.5 The result suggested that the uptake percent of $\mathrm{Cu}^{2+}$ could be affected by the composition of DCP in MLVs suspensions. We then examined the effect of the molar ratio of DCP in MLVs on the uptake percent of $\mathrm{Cu}^{2+}$. The total mol of PC, DCP and Chol dissolved 


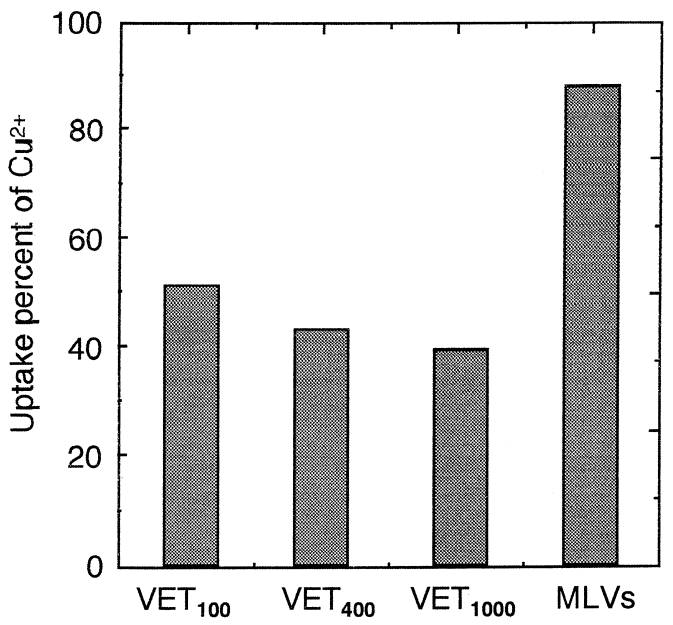

Fig. 2 Effect of the liposome size on the uptake percent of $\mathrm{Cu}^{2+}$. Conditions: liposome suspensions, $0.9 \mathrm{ml}$; solution of $\mathrm{Cu}^{2+}, 0.1 \mathrm{ml}$; mixing time, $30 \mathrm{~min}$.

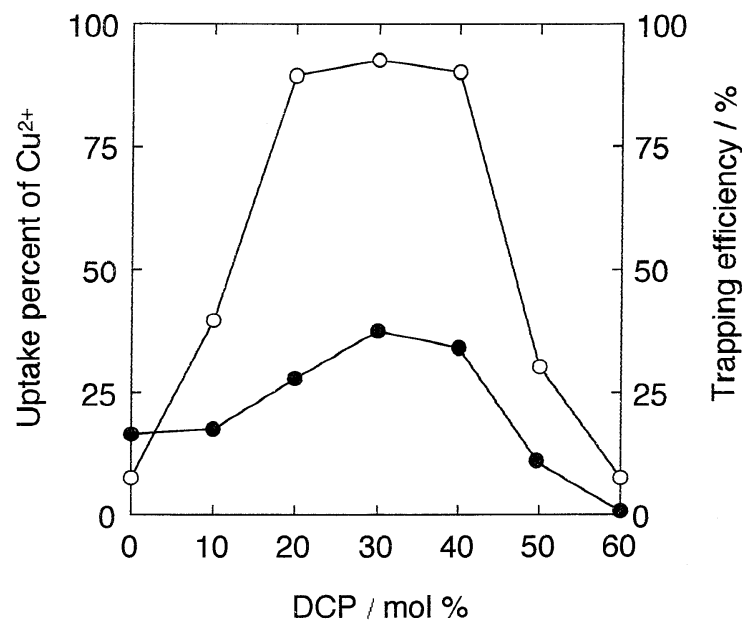

Fig. 3 Effect of the molar composition of DCP in MLVs on the uptake percent of $\mathrm{Cu}^{2+}$ and the trapping efficiency of calcein. Conditions: total mol of PC, Chol and DCP was kept constant at 42 $\mu \mathrm{mol}$ and the mol\% of Chol was kept constant at $30 \mathrm{~mol} \%$. (O) uptake of $\mathrm{Cu}^{2+} ;$ ( ) trapping efficiency of calcein.

in chloroform was kept constant at $42 \mu \mathrm{mol}$, and a molar ratio of Chol was kept constant at 30\%. On the other hand, DCP was dissolved in chloroform in the range of $0-60 \%$ at a molar ratio. The optimization curve for the molar ratio of DCP in MLVs is shown in Fig. 3. The uptake percent of $\mathrm{Cu}^{2+}$ exhibited a broad maximum at $30 \mathrm{~mol} \%$ of DCP. On the other hand, the uptake percent decreased above $40 \mathrm{~mol} \%$ of DCP. We then measured the trapping efficiency of calcein in MLVs according to the procedure in order to confirm the formation of liposomes in the range of $0-60 \%$ at a molar ratio of DCP. The trapping efficiency exhibited a broad maximum at $30 \mathrm{~mol} \%$ of DCP and decreased remarkably above $40 \mathrm{~mol} \%$ of DCP. Therefore, the decrease in the uptake percent above $40 \mathrm{~mol} \%$ of DCP can probably be attributed to the decrease in the yield of the MLVs. The optimum mol\% of DCP dissolved in chloroform was chosen to be $30 \mathrm{~mol} \%$.

\section{Distribution of $\mathrm{Cu}^{2+}$ into $\mathrm{MLVS}$}

The uptake of $\mathrm{Cu}^{2+}$ was due to complex formation between

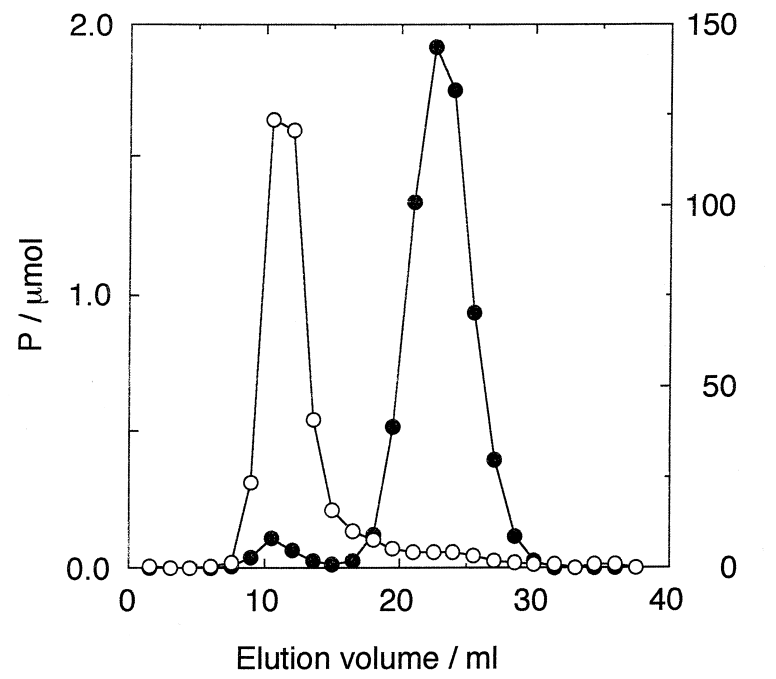

Fig. 4 Elution profiles of the $\mathrm{Cu}^{2+}$-EDTA complex and MLVs containing $\mathrm{Cu}^{2+}$ by gel-filtration. Conditions: column, Sephadex G-50 $(10 \times 300 \mathrm{~mm})$; mobile phase, $10 \mathrm{mM}$ Mops buffer $(\mathrm{pH} 7.5)$; MLVs suspensions, $275 \mu \mathrm{l}$; flow rate, $0.3 \mathrm{ml} / \mathrm{min}$; fractionation, $5 \mathrm{~min} / \mathrm{tube}$. ( $\mathrm{O})$, phosphorus; $(\bullet)$, copper.

$\mathrm{Cu}^{2+}$ and phosphate of DCP. Therefore, most of the $\mathrm{Cu}^{2+}$ could be localized on the surface of the MLVs, though $\mathrm{Cu}^{2+}$ was partly permeated into the interior side of the MLVs. ${ }^{5}$ We then determined the amount of $\mathrm{Cu}^{2+}$ on the outer membrane surface of the MLVs and on their interior side.

First, the total amount of $\mathrm{Cu}^{2+}$ distributed into the MLVs was determined after collecting MLVs containing $\mathrm{Cu}^{2+}$ by a Sephadex column according to the procedure. Next, a $0.1 \mathrm{ml}$ portion of a $2.0 \times 10^{-3} \mathrm{M}$ EDTA solution was added into the solution of the MLVs containing $\mathrm{Cu}^{2+}$, and the mixture was incubated for $30 \mathrm{~min}$ at $25^{\circ} \mathrm{C}$. EDTA was allowed to react with $\mathrm{Cu}^{2+}$ bounded to the phosphate ion of DCP on the outer membrane surface of the MLVs, since EDTA exists as anionic species under the experimental conditions, and liposomes are hardly permeable to ionic species. The thus-formed $\mathrm{Cu}^{2+}$ EDTA complex and MLVs containing $\mathrm{Cu}^{2+}$ on the interior side were separated by the Sephadex column. Figure 4 shows typical elution profiles of phosphorus and $\mathrm{Cu}^{2+}$. Two peaks appeared in the elution profile of $\mathrm{Cu}^{2+}$. When MLVs containing $\mathrm{Cu}^{2+}$ were eluted from the column, the elution volume of $\mathrm{Cu}^{2+}$ could coincide with that of phosphorus. Therefore, the first and second peaks were ascribed to the elution of MLVs containing $\mathrm{Cu}^{2+}$ and the $\mathrm{Cu}^{2+}$-EDTA complex, respectively. MLVs containing $\mathrm{Cu}^{2+}$ was mixing by collecting the fraction eluted from $9.5 \mathrm{ml}$ to $15 \mathrm{ml}$. We then determined the amount of $\mathrm{Cu}^{2+}$ incorporated into the interior side of the MLVs. Consequently, it was found that the $95 \%$ of the total vesicle $\mathrm{Cu}^{2+}$ was bound to DCP of the outer membrane surface, and that the remaining $5 \%$ of the total $\mathrm{Cu}^{2+}$ was distributed into the interior side of the MLVs. The effect of the mixing time on the formation of the $\mathrm{Cu}^{2+}$-EDTA complex was examined over the range of 10-60 min. The amount of $\mathrm{Cu}^{2+}$ bound to DCP of the outer membrane surface was independent of the mixing time examined. The distribution of $\mathrm{Cu}^{2+}$ into the interior side of the MLVs corresponded to a result previously obtained in which the permeation of $\mathrm{Cu}^{2+}$ into the inner phase of MLVs was confirmed by the fluorescence intensity of the calcein-time profile. $^{5}$ 
Uptake of transition-metal ions using MLVs

We previously investigated the uptake of $\mathrm{Mn}^{2+}, \mathrm{Co}^{2+}, \mathrm{Fe}^{2+}$, $\mathrm{Ni}^{2+}$ and $\mathrm{Zn}^{2+}$ using MLVs having a PC:DCP:Chol molar ratio of 10:1:10. ${ }^{5}$ The uptake percent of $\mathrm{Cu}^{2+}$ and $\mathrm{Zn}^{2+}$ was 18 and $6 \%$, respectively. However, the uptake was only little observed in the case of $\mathrm{Mn}^{2+}, \mathrm{Co}^{2+}, \mathrm{Fe}^{2+}$ and $\mathrm{Ni}^{2+}$. Therefore, MLVs composed of a PC:DCP:Chol molar ratio of 10:1:10 were unsuitable for the separation media of $\mathrm{Mn}^{2+}, \mathrm{Fe}^{2+}, \mathrm{Co}^{2+}$ and $\mathrm{Ni}^{2+}$. On the other hand, the uptake efficiency of $\mathrm{Cu}^{2+}$ was remarkably influenced by the concentration of DCP. We then examined the uptake of $\mathrm{Mn}^{2+}, \mathrm{Co}^{2+}, \mathrm{Fe}^{2+}, \mathrm{Ni}^{2+}$ and $\mathrm{Zn}^{2+}$ using MLVs composed of a PC:DCP:Chol molar ratio of 4:4:3.

The uptake percents of $\mathrm{Mn}^{2+}, \mathrm{Co}^{2+}, \mathrm{Ni}^{2+}$ and $\mathrm{Zn}^{2+}$ were 56, 24, 47 and $33 \%$, respectively. The uptake efficiency of $\mathrm{Zn}^{2+}$ increased remarkably compared to that using MLVs composed of a PC:DCP:Chol molar ratio of 10:1:10. In addition, MLVs composed of a PC:DCP:Chol molar ratio of 4:4:3 were used as the separation media for $\mathrm{Mn}^{2+}, \mathrm{Co}^{2+}$ and $\mathrm{Ni}^{2+}$. However, in the case of $\mathrm{Fe}^{2+}$, MLVs were condensed by mixing the $\mathrm{Fe}^{2+}$ solution. The difference in the uptake efficiency between metal ions could be ascribed to the difference in the ability for complex formation between the metal ions and the phosphate of DCP.

In conclusion, MLVs containing DCP were effective for the uptake of $\mathrm{Mn}^{2+}, \mathrm{Co}^{2+}, \mathrm{Ni}^{2+}, \mathrm{Cu}^{2+}$ and $\mathrm{Zn}^{2+}$. The uptake efficiency for metal ions was dependent on the molar ratio of
DCP in MLVs, since DCP played a role as a ligand for metal ions. A large portion of $\mathrm{Cu}^{2+}$ reacted with $\mathrm{DCP}$ on the surface of MLVs. Therefore, these results suggested that MLVs containing DCP could be applied to biomimetic metal-sorbing media.

\section{References}

1. B. Volesky and Z. R. Holan, Biotechnol. Prog., 1995, 11, 235.

2. F. Veglio' and F. Beolchini, Hydrometallurgy, 1997, 44, 301 .

3. J. H. van Zanten and H. G. Monbouquette, Biotechnol. Prog., 1992, 8, 546.

4. I. Stanish and H. G. Monbouquette, J. Membr. Sci., 2001, 192, 99

5. T. Kamidate, J. Yamaguchi, T. Suita, H. Tani, and H. Watanabe, Chem. Lett., 1997, 971.

6. H. Schott and F. A. A. Sayeed, J. Colloid Interface Sci., 1986, 112, 274.

7. N. Oku, D. A. Kendall, and R. C. Macdonald, Biochim. Biophys. Acta, 1982, 691, 332.

8. T. Kamidate, T. Suita, and H. Watanabe, Anal. Biochem., 1996, 241, 264. 